\title{
Analysis of the New Rural Cooperative Medical System and Its Countermeasures ${ }^{1}$
}

\author{
Lijun NIE \\ Politics and Public Administration Faculty of Yunnan Minzu University \\ Kunming, Yunnan, China 650031 \\ e-mail: 15808757473@163.com
}

\begin{abstract}
China's new rural cooperative medical system is different from the general medical insurance, it involves a large number of insured persons who living scattered with low economic level. The system has been carried out in vary widely geographical location, various economic status and medical conditions, so that there are many difficulties and problems in its development process. It is a brand new systematic project for establishment and perfection to improve the new rural cooperative medical system, we should always start from the organization and guidance of the government, the financial investment, the service capacity building of the rural primary health care institutions, and adjust the compensation scheme according to the actual situation of each region so that the participating farmers can benefit.
\end{abstract}

Keywords-New Rural Cooperative Medical System; Comparison; Countermeasure

\section{INTRODUCTION}

China's new rural cooperative medical system is the major disease-based medical mutual aid system, organized by the government's guidance and support; farmers participate in individual with the collective and government multi-financing. Since the implementation of the pilot project in 2003, it has made great achievements to help farmers to resist the risk of major diseases. To consolidate and develop the new rural cooperative medical system, promoting the development of rural medical and health undertakings and ensuring that all farmers enjoy basic medical and health services, are both important goals of building a new socialist countryside and a fundamental guarantee for promoting comprehensive rural progress.

\section{COMPARISON OF THE NEW AND THE PREVIOUS RURAL MEDICAL SYSTEM}

Compared with the previous rural medical system, the new rural cooperative medical system raises funds to take personal contributions, collective support and government funding with the implementation by a more transparent way, in which farmers pay less money while the compensation is more.

\section{A. Improvement in co-ordination of cooperative medical funds}

Rural cooperative medical funds in the past to farmers is mainly personal fund-raising, the new rural cooperative capital is the main financial investment in the country, supplemented by individual farmers. In this case, the co-ordination level is from the town-level co-ordination to the county-level co-ordination, and the total amount of funds has increased significantly, so the cooperative medical system enhances the ability to resist risks, which brings farmers a significant increase in the scope of medical treatment.

\section{B. Change of Cooperative medical management subject}

In the past, the management subject of rural cooperative medical care was mainly established by the township government, and the office funds were mainly or partly from the rural cooperative medical fund raised by the farmers. The management subject of the new rural cooperative medical system is the new rural cooperative management agencies established by the county government, and the office funds cannot be obtained from the new rural cooperative financing, but from the additional funding by the county government.

\section{Improvement in selection range and level of service institutions}

Whether the old rural cooperative medical system or the new rural cooperative medical system, the main medical service is relying on the township hospitals. The past rural cooperative medical system is not only trying to make "ailment treatment in the village, serious illness treatment in the country", but also providing for the township hospitals to transfer treatment for the serious illness. The new rural cooperative medical system make farmers have more choice to more medical hospital, and the medical institutions to treat diseases outside the township can also be a certain degree of reimbursement.

\section{PROBLEMS OF THE NEW RURAL COOPERATIVE MEDICAL SYSTEM}

Although China's new rural cooperative medical system has achieved gratifying effectiveness since its implementation, its soundness and perfection still face many difficulties and challenges, needing more exploration and practice.

\section{A. Weak awareness of health risk}

Because of the lack of risk awareness, farmers believe that their health is good, and if they participate in cooperative medical care with their own money for others to cure, which is not worth the candle. In addition, they are in low income level and believe that even if they are participating in the new rural cooperative medical system, they are still unable to pay high medical expenses if they

\footnotetext{
${ }^{1}$ This article is the stage results of Yunnan Provincial Institute of Nationalities General Project "the Investigation on Implementation of China's New Rural Cooperative Medical System and Its Development Research" (2015YB005).
} 
are concerned about the current level of protection of new rural cooperative medical care. The family economic situation and physical condition of farmers are important factors affecting the willingness to participate, although each person's participation fee is not high.

\section{B. High cost of the system operation}

At present, the collection of funds are carried out in a way that the cadres who are supervised collecting from house to house. Every year, the cumbersome collection and the cumbersome reimbursement procedures have increased the operating costs of the system. The new rural cooperative medical fund for the outpatient consumption of the family account is small, involving a wide range, needing identification, which has increased the management costs and the crisis of trust on the new rural cooperative medical system.

\section{Difficulties of the development of village medical institutions}

The state subsidizes various types of public health institutions and health personnel, but in rural areas, village clinics and village doctors are often excluded from the scope of higher subsidies. In the survey, it was learned that many administrative villages' clinics had received few subsidy from the higher authorities, and the operations of the village clinics were all private. Many village doctors did not get the material assistance from the higher authorities, and had never participated in the training of any organization, or even the technical support of the superior medical institution. Because of the less support provided to village health institutions, the role of village-level organizations in rural is limited. In addition, the capacity of village health institutions to provide public services is also limited.

\section{IMPROVEMENT OF THE NEW RURAL COOPERATIVE MEDICAL SYSTEM}

Since the beginning of the new century, the government has been committed to solving the problems of "difficult and expensive to see a doctor" and vigorously promoting the rural medical security system. The new rural cooperative medical system has been widely implemented as an important part of the construction of new socialist countryside.

\section{A. Promotion in equalization of basic public services}

We need strengthen the top design, establish a basic public service model with national conditions. First, to innovate the public service system, including compulsory education system, social security and social welfare system, public health care system, public income and public expenditure system, public service participation system, social cooperation system and so on. The second is to innovate the public service model, in accordance with fairness and justice, covering a wide range of appropriate and sustainable development requirements, speed up the construction of public service system. Third, to innovate public service supply mechanism with establishment of the diversified public service supply mechanism which is government-led, social participation, coordination and cooperation, efficient and flexible.

\section{B. Exploration of linkage protection mechanism for the stakeholder}

With the construction of medical, suffering, security, management mechanism, it's necessary to strengthen the village health room and other newly diagnosed medical network management, strengthen the vertical linkage between different levels of mechanisms to build a highly efficient service mechanism of medical institutions; enhance farmers' willingness to participate through scientific propaganda; establish democratic decision-making and diversification of interest expression mechanism, and promote the establishment of public service system as the focus of the government transformation; improve the level of government public service supply, keep the balance of interests of the main operation of the new rural cooperative system and the continuous development of norms.

\section{Improvement of the compensation mechanism}

For any kind of medical security system, the compensation is the final value of its part. The compensation mechanism design often determines the actual role and value of medical insurance system. First, the level of compensation should be moderately improved. The level of compensation and compensation for different medical institutions can be reformed according to actual needs. The proportion of urban hospitals should be appropriate to improve the proportion of compensation, because the patients in these hospitals are mostly for the treatment of more serious diseases, the corresponding medical costs are much higher than the treatment of other diseases. It is a very heavy financial burden for rural residents to choose to go to a large city hospital. Second, we need to simplify the reimbursement procedures and design more convenient way to pay. For ordinary participants, how to get reimbursement in the fastest time is the most practical problem.

\section{ACKNOWLEDGMENT}

This research was financially supported by Yunnan Provincial Institute of Nationalities.

\section{REFERENCES}

[1] Social Security in the 21st Century [M], publisher: New York: Oxford University Press, 1997.

[2] David M. Culter, Sarah J. Reber. Paying for Health Insurance: The Trade-Off between Competition and Adverse Selection [J]. The Quarterly Journal of Economics, Vol.113, No.2 (1998).

[3] (US) Janet V. Denhardt, Robert B. Denhardt. New Public Service: Service, not at the helm [M]. Ding Huang translation, Beijing: Renmin University Press, 2010.

[4] Yang LIU. Study on the Problem of Medical Security System in Minority Areas and Suggestions for Improvement [J]. Journal of Qinghai Ethnic Minorities, 2013 (4). (In Chinese)

[5] Yi CHENG. On the Reconstruction of New Rural Cooperative Medical System and Its Construction Practice[J]. Journal of Yunnan Nationalities University (Philosophy and Social Sciences), 2014 (4). (In Chinese) 